\title{
Surgical treatment of severe acute pancreatitis: After 15 years of practice
}

\author{
Jorge Pereira, Júlio Constantino, Liliana Duarte, \\ Helena Pinho, Luis Pinheiro
}

\begin{abstract}
Aims: We evaluated the surgical treatment of severe acute pancreatitis by analyzing the surgical methods and clinical outcomes during a 15-year period in our Department of Surgery with the goal of improving our performance. The aim of the study was to investigate the correlation between clinical factors and mortality in these patients. Methods: The study included the medical records of patients diagnosed with severe acute pancreatitis (Atlanta 2012 classification) who were surgically treated between 2000 and 2014 (15 years) in the Department of Cirurgia 1, Centro Hospitalar Tondela-Viseu in Portugal. The data were statistically analyzed using SPSS ${ }^{\circledR}$ Version 22 IBM ${ }^{\circledR}$ software. Results: A total of 39 patients were included, mostly men with an average age of 58.7 years. The most prevalent etiology was gallstones (41\% of cases). The following variables showed an independent relationship with mortality: age, length of stay, Ranson
\end{abstract}

Jorge Pereira ${ }^{1}$, Júlio Constantino ${ }^{1}$, Liliana Duarte ${ }^{2}$, Helena Pinho $^{3}$, Luis Pinheiro ${ }^{4}$

Affiliations: ${ }^{1}$ Surgical Specialist, Centro Hospitalar TondelaViseu, Viseu, Portugal; ${ }^{2}$ Surgical Resident, Centro Hospitalar Tondela-Viseu, Viseu, Portugal; ${ }^{3}$ Surgical Consultant, Centro Hospitalar Tondela-Viseu, Viseu, Portugal; ${ }^{4}$ Surgical Chief, Centro Hospitalar Tondela-Viseu, Viseu, Portugal.

Corresponding Author: Jorge de Almeida Pereira, Serviço de Cirurgia 1, Centro Hospitalar Tondela-Viseu, Avenida Rei D.Duarte, 3504-509 Viseu, Portugal; Tel: +35196636 4759; Email: docjota@netcabo.pt

Received: 16 March 2015

Accepted: 09 June 2015

Published: 10 August 2015 score, APACHE II (acute physiology and chronic health evaluation II) scores at admission and surgery, hematocrit, and renal, respiratory and cardiovascular failures. Conclusion: Findings are similar to those found in previous reports. The Ranson score and APACHE II scores are good prognostic factors for severe acute pancreatitis. Moreover, in this series, APACHE II at surgery appears to be the best predictor of mortality; a cut-off of 21 allowed for an $86.7 \%$ sensitivity and a $91 \%$ specificity.

Keywords: Acute pancreatitis, Multiple organ failure, Necrotizing pancreatitis, Surgery

\section{How to cite this article}

Pereira J, Constantino J, Duarte L, Pinho H, Pinheiro L. Surgical treatment of severe acute pancreatitis: After 15 years of practice. Int $J$ Hepatobiliary Pancreat Dis 2015;5:74-81.

Article ID: 100038IJHPDJP2015

$$
* * * * * * * * *
$$

doi:10.5348/ijhpd-2015-38-OA-13

\section{INTRODUCTION}

Acute pancreatitis is a common and usually benign disease with a low overall mortality rate [1]. However, local complications or organ failure can develop in certain patients, resulting in a life-threatening condition with a 
significantly higher mortality rate [2]. These complicated cases require significantly greater resources, including intensive care and surgery.

Severe acute pancreatitis, as defined by consensus at the Atlanta conference in 2012 [3, 4], is a microcirculatory condition leading to pancreatic necrosis; the necrosis is thought to be triggered during the early stages of the inflammatory cascade and is characterized by auto digestion of the gland [5]. The condition can cause abdominal infection, which accounts for 80\% [6] of deaths. Surgery is the currently accepted treatment for infection secondary to pancreatic necrosis $[7,8]$, though surgery exhibited little clinical impact on the mortality rate when it was first introduced decades ago [9-11].

Surgery for acute pancreatitis has undergone significant improvement over recent decades. During the 1960 s and 1970s, pancreatic resection was advocated as a method of eliminating the inflammation primum movens $[7,10,12]$. However, high postoperative mortality resulted in the technique being abandoned. New diagnostic and therapeutic options for pancreatitis emerged beginning in the late 1980s. The advent of computed tomography scan $[13,14]$ improved the characterization of necrosis and sped up the diagnosis of complications. New broadspectrum antibiotics with improved penetration into pancreatic tissue were also discovered [5, 12, 15-17], and the quality of critical care has undergone major improvement.

The Atlanta consensus conference in 1992 [18] was important in furthering the overall understanding of pancreatitis and in establishing a common terminology. The consensus standardized the approach and treatment of pancreatitis in treatment centers worldwide and represents a significant step forward.

Necrosectomy was introduced as a surgical treatment for acute pancreatitis in the late 1980 s [7, 19, 20] and has remained the preferred technique through to the present day. Initially, the technique required a formal laparotomy, but currently, many clinicians advocate minimally invasive or combined techniques [21-23]. Regardless, necrosectomy remains the gold standard for the treatment of infected pancreatic necrosis. In the early days of its use, necrosectomy was also recommended for sterile necrosis, but this is no longer recommended [7, 24].

Unfortunately, much remains unknown about infected pancreatic necrosis including its origin, factors promoting progression, and the ideal treatment. These questions may take some time to answer, but at present, clinicians must continue to treat affected patients using the best knowledge, technology, and expertise available.

In this study, we evaluated the surgical treatment for severe acute pancreatitis by analyzing the surgical methods and clinical outcomes over a 15-year period at our institution with the goal of improving our performance; the aim of the study was to investigate the correlation between clinical factors and mortality in patients submitted to surgical treatment for severe acute pancreatitis

\section{MATERIALS AND METHODS}

\section{Study population}

The study included the medical records of patients diagnosed with severe acute pancreatitis (Atlanta 2012 Classification) who were treated surgically between 2000 and 2014 (15 years) in the Department of Cirurgia 1, Centro Hospitalar Tondela-Viseu in Portugal. The study period overlapped with the launch of the intensive care unit at the hospital. A total of 39 patients were included in the study. The hospital has two Departments of General Surgery with similar caseloads, and the sample population reflects approximately half of the full case volume for this particular patient population at the hospital.

\section{Statistical analysis}

Thirty-one variables were analyzed, including demographic, clinical, prognostic factors, and therapeutic outcomes (clinical cure versus deceased); these parameters are detailed in Tables 1 and 2.

Data were statistically analyzed using SPSS $^{\circledR}$ version 22 IBM $^{\circledR}$ software. The normality of the distribution for each variable was determined using the Shapiro-Wilk test. Variables with a normal distribution were subjected to univariate analysis with the parametric Student t-test, and variables without normal distribution were analyzed with the nonparametric Mann-Whitney test and the chi-square test. For multivariate analysis, a multiple linear model was employed. We then calculated receiver operating characteristic curves for variables that were identified as potential prognostic factors to identify possible cut-off values.

\section{Descriptive study}

During the study period, 1702 acute pancreatitis patients were hospitalized, and 39 patients were diagnosed with severe acute pancreatitis [18] and underwent surgery. The sample population was primarily male, and the most prevalent etiology was gallstones. The descriptive analysis is summarized in Tables 1 and 2.

\section{Case presentation and progression}

Patients typically presented to the emergency room early in the disease course with complaints of abdominal pain. The mean duration of symptoms before seeking medical attention was $<1$ day. Analysis of several early prognostic markers was included in the study, including the Ranson score [25], the APACHE II (acute physiology and chronic health evaluation II) score [26, 27], the C-reactive protein [28] (CRP) at $48 \mathrm{~h}$, and the hematocrit at admission [29, 30].

Most patients (35/39) underwent an abdominal contrast-enhanced computed tomography (CT) scan 
after a median 3.4 days. Although the median time was generally suitable for performing the first CT scan [4, 13], in some cases, the initial CT scan was performed as long as 18 days after admission. Necrosis was identified in patients undergoing CT scan, defined as a pancreatic parenchymal area without contrast enhancement [4].

Additionally, the patients developing multiple organ failure were identified [4, 31, 32] and classified according to the different organ failures suffered: respiratory, renal, cardiovascular, hematologic, neurologic, hepatic or multiple.

Twenty-four of thirty-nine (61.5\%) patients were diagnosed with pancreatic infection based on tissue or fluid culture. Gram-negative bacteria were identified in $\mathbf{2 3 . 1 \%}$ of samples; Gram-positive bacteria in $33.3 \%$, and anaerobic species in $5.1 \% ; 38.1 \%$ of samples were negative on culture.

\section{Preoperative treatment}

Empirical antibiotic prophylaxis was not used in $35.9 \%$ of cases. Antibiotics were used as follows in the remaining $64.1 \%$ of cases: carbapenem $(33.3 \%)$, piperacillin-tazobactam (10.3\%), cephalosporin (10.3\%), fluoroquinolone (2.6\%), metronidazole (2.6), and other (40.9\%).

Antibiotic therapy was initiated before or after surgery depending on when infection was diagnosed. Once an infectious agent was identified, the distribution of selected antibiotics differed as follows: carbapenem (66.7\%), piperacillin-tazobactam (10.3\%), cephalosporin (5.1\%), metronidazole combined with a second agent (7.9\%), fluoroquinolones (2.6\%), and other (2.6\%). In addition, $38.5 \%$ of patients also received an antifungal agent.

\section{Surgical intervention}

Most patients (19 cases) underwent surgery due to infection of pancreatic or peripancreatic necrosis. The diagnosis of infection was achieved by a computed tomography scan. If the computed tomography scan revealed no signs of infection, diagnosis was assumed in all patients with poor clinical progression in association with inflammatory parameters elevation, such as CRP and procalcitonin. The remaining patients were surgically treated after developing abdominal compartment syndrome (9 cases) [33], multiple organ failure unresponsive to the best intensive care therapy (4 cases) or bleeding with hemodynamic instability ( 2 cases). A small group of patients with abdominal signs of peritoneal irritation (5 cases) were submitted to exploratory laparotomy without previous diagnosis. The existence of acute pancreatitis was noted intraoperatively.

Surgery was performed at different points of evolution of the disease, depending on individual clinical factors. Multiple organ failure and abdominal compartment syndrome were the most common indications in patients who underwent surgery during the first two weeks of disease. Those who were surgically treated after the first two weeks of disease were typically treated because of infection. A total of 24 patients underwent surgery to treat confirmed infection; of these, $41.6 \%$ of procedures were performed during the first two weeks of disease.

Most patients underwent a median laparotomy, and the remainder underwent transverse subcostal laparotomy.

The most common procedure was fluid collection drainage followed by necrosectomy. Abdominal decompression without any additional procedures was performed once in a case of abdominal compartment syndrome.

\section{RESULTS}

\section{Morbidity and prognostic factors}

The patient population had elevations in several early prognostic markers. The mean Ranson score was 5.1 [25], indicating a predictable $40 \%$ mortality, and the mean APACHE II score was 10.7 [26, 27], which indicated a 15\% expected mortality.

Surgical complications occurred in $38.5 \%$ of cases, including intestinal necrosis (17.9\%), digestive fistula (10.3\%), and hemorrhage (2.6\%). Nine of 24 survivors (23.1\%) developed severe sequelae, including respiratory dysfunction, incisional hernia, digestive fistula, and dependence in everyday activities.

The mean length of stay was 57 days with a maximum of 154 days. The mean length of stay in the intensive care unit (ICU) was 23.5 days with a maximum of 136 days. The length of stay in the ICU did not influence the mortality. The hospital mortality was $38.5 \%$.

The univariate analysis identified a relationship between mortality and the following variables (Table 3): age, length of stay, Ranson score, APACHE II score at admission, APACHE II score at surgery, hematocrit on day 1, Atlanta 2012 classification [4], concurrent multiple organ failure, renal failure, respiratory failure, cardiovascular failure, and antibiotic therapy. The multivariate analysis revealed that mortality was independently correlated with age, length of stay, Ranson score, APACHE II scores at admission and surgery, hematocrit, and renal, respiratory, and cardiovascular failure (Table 4). Multiple organ failure, the Atlanta 2012 classification, and antibiotic therapy were not independently associated with mortality.

Thus, the receiver operating characteristic curves were generated to confirm the presence of a significant correlation between mortality and the following factors: age, length of stay, Ranson score, hematocrit and APACHE II score (Figure 1). Patient age showed a clear relationship with mortality; the median age was significantly higher in deceased patients compared with surviving patients (68 years versus 52.5 years, respectively; $p=0.048$ ). 
Table 1: Descriptive analysis $(n=39)$ : demographic characteristics, clinical progression and outcome.

\begin{tabular}{|c|c|}
\hline \multicolumn{2}{|l|}{ Variables } \\
\hline Age (Average- min/max) & $58.71(25 / 86)$ \\
\hline Gender M/F & $25 / 14$ \\
\hline \multicolumn{2}{|l|}{ Etiology } \\
\hline Gallstones & $16(41 \%)$ \\
\hline Ethanol & $11(28,2 \%)$ \\
\hline Mixed & 3 \\
\hline Other & 9 \\
\hline \multicolumn{2}{|l|}{$\begin{array}{l}\text { Case evolution (Average days - } \\
\min / \max \text { ) }\end{array}$} \\
\hline Presentation & $1(0 / 11)$ \\
\hline Length of stay & $57(1 / 154)$ \\
\hline $\begin{array}{l}\text { Length of stay in Intensive } \\
\text { care }\end{array}$ & $25.51(0 / 136)$ \\
\hline Wait until first CT & $3.4(0 / 18)$ \\
\hline \multicolumn{2}{|l|}{$\begin{array}{l}\text { Prognostic indexes at } \\
\text { admittance (Average - min/ } \\
\operatorname{max)}\end{array}$} \\
\hline Ranson & $5.17(1 / 9)$ \\
\hline $\mathrm{CRP} 48 \mathrm{~h}$ & $29.12(10.5 / 55.7)$ \\
\hline APACHE II day1 & $10.71(0 / 29)$ \\
\hline Balthazar & $3.42(1 / 7)$ \\
\hline Hematocrit day1 & $43.30(28.3 / 60)$ \\
\hline \multicolumn{2}{|l|}{ Atlanta 2012} \\
\hline Mild & o \\
\hline Moderate & $20.5 \%$ \\
\hline Severe & $79.5 \%$ \\
\hline \multicolumn{2}{|l|}{ Complications: } \\
\hline \multicolumn{2}{|l|}{ Necrosis } \\
\hline Without necrosis & $53.8 \%$ \\
\hline $30 \%$ & $12.8 \%$ \\
\hline 30 a $50 \%$ & $7.7 \%$ \\
\hline$>50 \%$ & $17.9 \%$ \\
\hline MOF & $79.5 \%$ \\
\hline Respiratory OF & $71.8 \%$ \\
\hline Renal OF & $43.6 \%$ \\
\hline Cardiovascular OF & $66.7 \%$ \\
\hline Hematologic OF & $17.9 \%$ \\
\hline Neurologic OF & $15.4 \%$ \\
\hline Liver OF & $15.4 \%$ \\
\hline Infection & $61.5 \%$ \\
\hline \multicolumn{2}{|l|}{ Sequelae } \\
\hline Without sequelae & $76.9 \%$ \\
\hline Respiratory dysfunction & $2.6 \%$ \\
\hline Incisional hernia & $7.7 \%$ \\
\hline $\begin{array}{l}\text { Persistent digestive/ } \\
\text { pancreatic fistula }\end{array}$ & $10.3 \%$ \\
\hline $\begin{array}{l}\text { Every day activities need of } \\
\text { help }\end{array}$ & $2.6 \%$ \\
\hline
\end{tabular}

Abbreviations: CRP, C reactive protein; MOF, multiple organ failure; OF, organ failure; M, male; F, female

However, although the area under the curve (AUC) had an acceptable discriminative power (0.71), it did not allow calculation of a cut-off with acceptable sensitivity and specificity. A similar outcome was observed for the length of stay (AUC $=0.21)$, APACHE II score at admission $(\mathrm{AUC}=0.73)$, and hematocrit $(\mathrm{AUC}=0.683)$. The shorter length of stay in deceased patients likely
Table 2: Descriptive analysis $(n=39)$ : case evolution during perioperative period.

\begin{tabular}{ll}
\hline Time of surgery & \\
$\quad$ Within 2 weeks & $53.8 \%$ \\
2 a 4 weeks & $17.9 \%$ \\
> 4 weeks & $28.2 \%$ \\
APACHE II day of surgery (average - min/max) & $17.97(5 / 39)$ \\
ERCP & $10 \%$ \\
Indication & \\
MOF & $10.3 \%$ \\
Infection & $48.7 \%$ \\
ACS & $23.1 \%$ \\
Diagnosis & $12.8 \%$ \\
Hemorrhage & $5.1 \%$ \\
Laparotomy & \\
Transverse & $28.2 \%$ \\
Median & $71.8 \%$ \\
Closure & \\
Primary & $43.6 \%$ \\
Laparostomy & $56.4 \%$ \\
Number of interventions (Average - min/max) & $2.4(1 / 9)$ \\
Procedure & \\
$\quad$ Necrosectomy & $43.6 \%$ \\
Drainage & $53.8 \%$ \\
Decompress & $2.6 \%$ \\
Surgical complications & $38.5 \%$ \\
Mortality & $38.5 \%$ \\
\hline
\end{tabular}

Abbreviations: ERCP endoscopic retrograde cholangiopancreatography, MOF multiple organ failure, ACS abdominal compartment syndrome

Table 3: Influence of various clinical factors on mortality according to univariate analysis.

\begin{tabular}{ll} 
& $\boldsymbol{p}$ \\
\hline Age & 0.016 \\
Gender & $\mathrm{ns}$ \\
Etiology & $\mathrm{ns}$ \\
Presentation & $\mathrm{ns}$ \\
Length of stay & 0.002 \\
Length of stay in Intensive Care & $\mathrm{ns}$ \\
Score of Ranson & 0.000 \\
CRP & $\mathrm{ns}$ \\
APACHE II day 1 & 0.009 \\
APACHE II day of surgery & 0.000 \\
Balthazar & $\mathrm{ns}$ \\
Necrosis & $\mathrm{ns}$ \\
Hematocrit & 0.033 \\
Atlanta 2012 & 0.014 \\
MOF & 0.013 \\
Respiratory OF & 0.002 \\
Renal OF & 0.003 \\
Cardiovascular OF & 0.001 \\
Hematologic OF & $\mathrm{ns}$ \\
Neurologic OF & $\mathrm{ns}$ \\
Liver OF & $\mathrm{ns}$ \\
Infection & $\mathrm{ns}$ \\
Time of surgery & $\mathrm{ns}$ \\
Surgical indication & $\mathrm{ns}$ \\
Antibioprophylaxis & $\mathrm{ns}$ \\
Antibiotherapy & 0.024 \\
Flora & $\mathrm{ns}$ \\
\hline
\end{tabular}

Abbreviations: CRP C-reactive protein, MOF multiple organ failure, OF organ failure 
Table 4: Influence of various clinical factors on mortality according to multivariate analysis.

\begin{tabular}{lll} 
& $p$ & Odds ratio (CI 95\%) \\
\hline Age & 0,008 & 16.90 \\
Length of stay & 0,005 & -39.25 \\
Score of Ranson & 0,000 & 2.23 \\
APACHE II day 1 & 0,020 & 5.38 \\
APACHE II day of surgery & 0,000 & 14.07 \\
Hematocrit & 0,023 & 5.03 \\
Atlanta 2012 & $\mathrm{ns}$ & \\
MOF & $\mathrm{ns}$ & \\
Respiratory OF & 0,010 & -0.38 \\
Renal OF & 0,008 & -0.45 \\
Cardiovascular OF & 0,002 & -0.47 \\
Antibiotherapy & $\mathrm{ns}$ & \\
\hline
\end{tabular}

Abbreviations: MOF multiple organ failure, Atlanta 2012, current guidelines for diagnosing severe acute pancreatitis

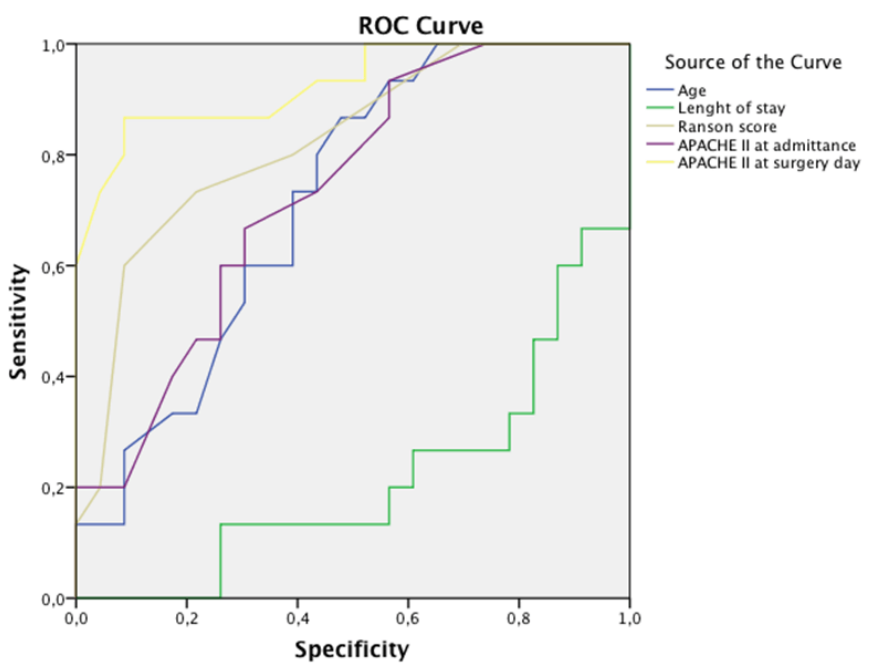

Figure 1: Receiver operating characteristic curves for quantitative variables with a strong correlation to mortality.

reflects their lower survival rate and may not indicate a direct relationship with mortality.

The AUC analysis for the Ranson score (AUC $=0.83$ ) and APACHE II at surgery (AUC $=0.92)$ generated cutoff values with acceptable sensitivity and specificity; therefore, these two parameters served as predictors for mortality in this study. In patients undergoing surgery for severe acute pancreatitis, the Ranson score cut-off was 5 (sensitivity $80 \%$ and specificity $61 \%$ ). The statistical relationship was stronger for the APACHE II score at surgery; a cut-off of 21 allowed for an $86.7 \%$ sensitivity and a $91 \%$ specificity.

The lack of association between multiple organ failure and mortality was unsurprising as multiple organ failure directly depends on individual organ failure [32]. Both individual and multiple organ failure influence mortality. This same phenomenon was observed for multiple organ failure at the Atlanta 2012 consensus. The statistical significance of each individual organ failure (renal, respiratory, and cardiovascular) reflects their high prevalence in deceased patients; respiratory and cardiovascular failure was present in all deceased patients, and renal failure was present in $75 \%$ of the deceased. Patients who did not develop these types of organ failure generally survived; only four patients who did not develop renal failure died. A total $53 \%$ of patients with respiratory failure died, $64 \%$ with renal failure died, and $57 \%$ of patients with cardiovascular failure died.

The use of prophylactic antibiotics did not influence the incidence of subsequent infection or prognosis.

The type of laparotomy was not correlated with the overall rate of complications. However, transverse laparotomy was associated with a higher sequelae rate compared with median laparotomy (54.5\% versus $10.7 \%$, respectively).

The use of laparostomy did not influence the clinical outcome, the incidence of complications, or the rate of sequelae. The number of procedures was not correlated with the incidence of complications or sequelae.

\section{DISCUSSION}

This study includes several conceptual flaws that should be considered when interpreting the present findings, namely its retrospective nature and small sample size. Another critical limitation in the present study is the absence of cases employing minimally invasive treatment of complicated pancreatitis, which are becoming increasingly commonplace [21-23]. This case distribution may reflect practices unique to the study locale in which all clinicians within the department treated pancreatitis patients during the study period. This distribution is likely to change as the department has since been segregated into organ-specific subgroups.

The descriptive findings of this study are similar to those in previous reports [11, 34]. Notably, the present study is a purely surgical series, which resulted in elevations in several prognostic factors including the Ranson score, APACHE II score, and the CRP. The mean values in the present sample population were well above the cut-offs considered high risk for severe acute pancreatitis [35, 36]. Consequently, the incidence of multiple organ failure is also high.

Prophylactic use of antibiotics remains controversial. Although there is no evidence that prophylaxis improves prognosis $[6,12,16,37,38]$, some reports continue to recommend systemic antibiotic use [6, 12, 38]. This case series occurred during several trends concerning the use and selection of prophylactic antibiotics. Currently, carbapenems and fluoroquinolones are the antibiotics of choice because of their improved ability to penetrate the pancreatic tissue compared with other agents [4, 17]. However, with the high rate of fluoroquinolone resistance that has developed in Escherichia coli in Portugal [39], its use may need to be reconsidered in these cases, as should the use of carbapenems as prophylactic antibiotics.

Surgical intervention should be delayed as long as possible $[3,4,7,8,22]$. The relationship between early 
surgery and mortality is evident in several studies [7, 22]. We did not observe this relationship in the current series, but the relationship between the surgical indication and the time of surgery was evident. Patients with abdominal compartment syndrome or multiple organ failure generally underwent surgery sooner. Before the Atlanta 2012 guidelines emerged, severe acute pancreatitis with organ failure at presentation was described as critical acute pancreatitis in several reports [40, 41] because of its high mortality rate. This designation did not persist, but the term remains important regardless. Notably, the rate of patients with infectious pancreatitis who underwent surgery early during the disease course was 41.6\%; this trend contradicts earlier studies, which report that infection typically appears late in the disease course, usually after the 3 rd week [22, 31, 42].

One of the interesting trends revealed in this study is in the comparison between laparotomy techniques; the present findings could serve as a springboard for a prospective study examining the differing outcomes between median and transverse laparotomy. Based on several studies by Leppäniemi concerning the utility of transverse laparotomy [ 43,44$]$, we began employing the technique and favored some of its advantages, particularly the good access to the pancreatic fossa. However, data in this series showed greater association with sequelae, though the rate of complications did not increase.

The rate of complications in this series is similar to those previously described [11,34], particularly the long hospital and ICU length of stay. The mortality rate is slightly higher than those in recent reports [11, 21]. Recent studies that employ combined surgical approaches [21] (i.e., minimally invasive procedure followed by combined or open technique if indicated - step up approach) report better outcomes. As already discussed, the present series did not include cases employing minimally invasive procedures, which we suspect underlies the comparatively higher mortality in the current population.

Most notably, the current findings validate the Ranson score and APACHE II score as prognostic factors, especially the APACHE II score at surgery. There are no known studies describing the prognostic significance of the APACHE II score at surgery, at least none reporting the level of statistical significance observed in this series.

The relationship between prognosis, multiple organ failure, and respiratory, circulatory, and renal failure is well documented in surgically and medically treated patients. These factors share an interconnected relationship with systemic inflammatory response syndrome and sepsis that is undoubtedly multifactorial. However, it should be emphasized that the absence of multiple organ failure is, in fact, related with patient's survival. This facet led to the addition of a second classification of severity in acute pancreatitis, known as moderate acute pancreatitis, which is reserved for cases with local complications or temporary organ failure [4].

\section{CONCLUSION}

Findings are similar to those found in previous reports. The Ranson score and APACHE II (acute physiology and chronic health evaluation II) scores are good prognostic factors for severe acute pancreatitis. Moreover, in this series, APACHE II at surgery appears to be the best predictor of mortality; a cut-off of 21 allowed for an $86.7 \%$ sensitivity and a $91 \%$ specificity.

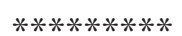

\section{Author Contributions}

Jorge Pereira - Substantial contributions to conception and design, Acquisition of data, Analysis and interpretation of data, Drafting the article, Revising it critically for important intellectual content, Final approval of the version to be published

Júlio Constantino - Substantial contributions to conception and design, Acquisition of data, Analysis and interpretation of data, Drafting the article, Revising it critically for important intellectual content, Final approval of the version to be published

Liliana Duarte - Substantial contributions to conception and design, Acquisition of data, Analysis and interpretation of data, Drafting the article, Revising it critically for important intellectual content, Final approval of the version to be published

Helena Pinho - Substantial contributions to conception and design, Acquisition of data, Analysis and interpretation of data, Drafting the article, Revising it critically for important intellectual content, Final approval of the version to be published

Luis Pinheiro - Substantial contributions to conception and design, Acquisition of data, Analysis and interpretation of data, Drafting the article, Revising it critically for important intellectual content, Final approval of the version to be published

\section{Guarantor}

The corresponding author is the guarantor of submission.

\section{Conflict of Interest}

Authors declare no conflict of interest.

\section{Copyright}

(C) 2015 Jorge Pereira et al. This article is distributed under the terms of Creative Commons Attribution License which permits unrestricted use, distribution and reproduction in any medium provided the original author(s) and original publisher are properly credited. Please see the copyright policy on the journal website for more information. 


\section{REFERENCES}

1. Gardner TB, Vege SS, Pearson RK, Chari ST. Fluid resuscitation in acute pancreatitis. Clin Gastroenterol Hepatol 2008 Oct;6(10):1070-6.

2. Heinrich S, Schäfer M, Rousson V, Clavien PA. Evidence-based treatment of acute pancreatitis: a look at established paradigms. Ann Surg 2006 Feb;243(2):154-68.

3. Sarr MG, Banks PA, Bollen TL, et al. The new revised classification of acute pancreatitis 2012. Surg Clin North Am 2013 Jun;93(3):549-62.

4. Banks PA, Bollen TL, Dervenis C, et al. Classification of acute pancreatitis--2012: revision of the Atlanta classification and definitions by international consensus. Gut 2013 Jan;62(1):102-11.

5. Pandol SJ, Saluja AK, Imrie CW, Banks PA. Acute pancreatitis: bench to the bedside. Gastroenterology 2007 Mar;132(3):1127-51.

6. De Campos T, Assef JC, Rasslan S. Questions about the use of antibiotics in acute pancreatitis. World $\mathrm{J}$ Emerg Surg 2006 Jul 4;1:20.

7. Bradley EL III. Surgery of acute pancreatitis; Am J Surg 2007;194 (suppl to Oct):S20-S23.

8. Martin RF, Hein AR. Operative management of acute pancreatitis. Surg Clin North Am 2013 Jun;93(3):595610.

9. Fernández-Cruz L, Navarro S, Valderrama R, et al. Acute necrotizing pancreatitis: a multicenter study. Hepatogastroenterology 1994 Apr;41(2):185-9.

10. Kivilaakso E, Fräki O, Nikki P, Lempinen M. Resection of the pancreas for acute fulminant pancreatitis. Surg Gynecol Obstet 1981 Apr;152(4):493-8.

11. Schneider L, Büchler MW, Werner J. Acute pancreatitis with an emphasis on infection. Infect Dis Clin North Am 2010 Dec;24(4):921-41, viii.

12. Busquets J, Peláez N, Secanella L, et al. Evolution and results of the surgical management of 143 cases of severe acute pancreatitis in a referral centre. Cir Esp 2014 Nov;92(9):595-603.

13. De Waele JJ, Delrue L. Severity prediction in acute pancreatitis: the role of early CT scan. Abdom Imaging 2007 Mar-Apr;32(2):265-6.

14. Balthazar EJ. CT diagnosis and staging of acute pancreatitis. Radiol Clin North Am 1989 Jan;27(1):1937 .

15. Tenner S, Baillie J, DeWitt J, Vege SS. American College of Gastroenterology guideline: management of acute pancreatitis. Am J Gastroenterol 2013 Sep;108(9):1400-15; 1416.

16. Bradley EL 3rd. Antibiotics in acute pancreatitis. Current status and future directions. Am J Surg 1989 Nov;158(5):472-7; discussion 477-8.

17. Büchler $\mathrm{M}$, Malfertheiner $\mathrm{P}$, Friess $\mathrm{H}$, et al. The penetration of antibiotics into human pancreas. Infection 1989 Jan-Feb;17(1):20-5.

18. Bradley EL 3rd. A clinically based classification system for acute pancreatitis. Summary of the International Symposium on Acute Pancreatitis, Atlanta, Ga, September 11 through 13, 1992. Arch Surg 1993 May;128(5):586-90.

19. Beger HG, Büchler M, Bittner R, Block S, Nevalainen T, Roscher R. Necrosectomy and postoperative local lavage in necrotizing pancreatitis. Br J Surg 1988
Mar;75(3):207-12

20. Frey CF. How I do it - Necrosectomy in acute pancreatitis. J HBP Surg 1994;1(2):155-158.

21. van Santvoort HC, Besselink MG, Bakker OJ, et al. A step-up approach or open necrosectomy for necrotizing pancreatitis. N Engl J Med 2010 Apr 22;362(16):1491-502.

22. Mentula P, Leppäniemi A. Position paper: timely interventions in severe acute pancreatitis are crucial for survival. World J Emerg Surg 2014 Feb 10;9(1):15.

23. Amano $\mathrm{H}$, Takada $\mathrm{T}$, Isaji $\mathrm{S}$, et al. Therapeutic intervention and surgery of acute pancreatitis. J Hepatobiliary Pancreat Sci 2010 Jan;17(1):53-9.

24. Rocha FG, Balakrishnan A, Ashley SW, Clancy TE. A historic perspective on the contributions of surgeons to the understanding of acute pancreatitis. Am J Surg 2008 Sep;196(3):442-9.

25. Ranson JH, Rifkind KM, Roses DF, Fink SD, Eng K, Spencer FC. Prognostic signs and the role of operative management in acute pancreatitis. Surg Gynecol Obstet 1974 Jul;139(1):69-81.

26. Lee WS, Huang JF, Chuang WL. Outcome assessment in acute pancreatitis patients. Kaohsiung J Med Sci 2013 Sep;29(9):469-77.

27. Larvin M, McMahon MJ. APACHE-II score for assessment and monitoring of acute pancreatitis. Lancet $1989 \mathrm{Jul}$ 22;2(8656):201-5.

28. Pongprasobchai S, Jianjaroonwong V, Charatcharoenwitthaya P, et al. Erythrocyte sedimentation rate and C-reactive protein for the prediction of severity of acute pancreatitis. Pancreas 2010 Nov;39(8):1226-30.

29. Wilson C, Heads A, Shenkin A, Imrie CW. C-reactive protein, antiproteases and complement factors as objective markers of severity in acute pancreatitis. $\mathrm{Br}$ J Surg 1989 Feb;76(2):177-81.

30. Banks PA, Freeman ML. Practice guidelines in acute pancreatitis. Am J Gastroenterol 2006 Oct;101(10):2379-400.

31. Beger HG, Rau BM. Severe acute pancreatitis: Clinical course and management. World J Gastroenterol 2007 Oct 14;13(38):5043-51.

32. Marshall JC, Cook DJ, Christou NV, Bernard GR, Sprung CL, Sibbald WJ. Multiple organ dysfunction score: a reliable descriptor of a complex clinical outcome. Crit Care Med 1995 Oct;23(10):1638-52.

33. Gecelter G, Fahoum B, Gardezi S, Schein M. Abdominal compartment syndrome in severe acute pancreatitis: an indication for a decompressing laparotomy? Dig Surg 2002;19(5):402-4; discussion 404-5.

34. Wormer BA, Swan RZ, Williams KB, et al. Outcomes of pancreatic debridement in acute pancreatitis: analysis of the nationwide inpatient sample from 1998 to 2010. Am J Surg 2014 Sep;208(3):350-62.

35. Charbonney E, Nathens AB. Severe acute pancreatitis: a review. Surg Infect (Larchmt) 2008 Dec;9(6):5738.

36. Yang CJ, Chen J, Phillips AR, Windsor JA, Petrov MS. Predictors of severe and critical acute pancreatitis: a systematic review. Dig Liver Dis 2014 May;46(5):44651.

37. Nicholson LJ. Acute pancreatitis: should we use antibiotics? Curr Gastroenterol Rep 2011 Aug;13(4):336-43. 
38. Uhl W, Warshaw A, Imrie C, et al. IAP Guidelines for the Surgical Management of Acute Pancreatitis. Pancreatology 2002;2(6):565-73.

39. Correia C, Costa E, Peres A, Alves M, Pombo G, Estevinho L. Etiology of urinary tract infections and antimicrobial susceptibility of urinary pathogens. Acta Med Port 2007 Nov-Dec;20(6):543-50.

40. Petrov MS, Windsor JA. Classification of the severity of acute pancreatitis: how many categories make sense? Am J Gastroenterol 2010 Jan;105(1):74-6.

41. Isenmann R, Rau B, Beger HG. Early severe acute pancreatitis: characteristics of a new subgroup. Pancreas 2001 Apr;22(3):274-8.
42. Beger HG, Bittner R, Block S, Büchler M. Bacterial contamination of pancreatic necrosis. A prospective clinical study. Gastroenterology 1986 Aug;91(2):4338.

43. Leppäniemi A. Open Abdomen after Severe Acute Pancreatitis. Eur J Trauma Emerg Surg 2008;34(1):17-23.

44. Leppäniemi A, Mentula P, Hienonen P, Kemppainen E. Transverse laparostomy is feasible and effective in the treatment of abdominal compartment syndrome in severe acute pancreatitis. World J Emerg Surg 2008 Jan 30;3:6.
Access full text article on other devices

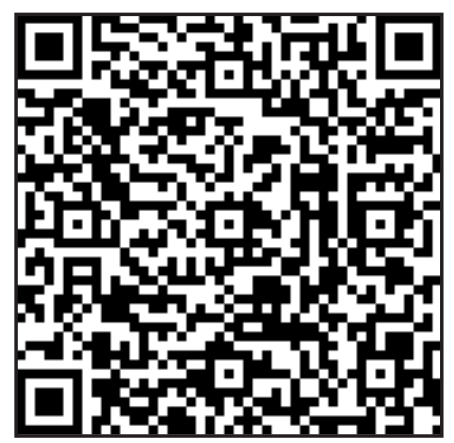

Access PDF of article on other devices

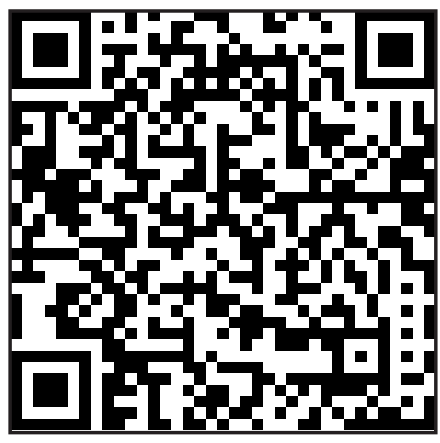

